\title{
The anisotropy of Leighton Buzzard sand under general stress conditions
}

\author{
P.J. Naughton \\ National University of Ireland, Galway, Ireland \\ B.C. O'Kelly \\ Trinity College, University of Dublin, Ireland, formally Scott Wilson, UK
}

\begin{abstract}
A hollow cylinder apparatus was used to investigate the inherent anisotropy and membrane penetration of Leighton Buzzard sand test-specimens. The degree of inherent anisotropy was found to be independent of the mean effective stress but dependent on the initial relative density of the test-specimen. In the vertical-tohorizontal directions, the degree of inherent anisotropy decreases with increasing relative density. A wet-pluviation, sample preparation technique produces cross-anisotropic test-specimens, with the degree of cross anisotropy independent of the initial relative density. The effects of membrane penetration (expressed in terms of the normalized unit membrane penetration) are found to be independent of the initial relative density and the mean effective stress.
\end{abstract}

\section{INTRODUCTION}

Most sedimentary soils are inherently anisotropy. Their response to loading will depend on the magnitude and the direction of the induced principal stresses. The hollow cylinder apparatus (HCA) is the only soillaboratory test device that can facilitate independent control of both the magnitude and the direction of the principal stresses. The stress history and loading conditions at a particular point in the ground can be reproduced on a hollow cylindrical test-specimen and its constitute behaviour and pore pressure response measured. This makes the HCA ideal for investigating anisotropic mechanical behaviour.

Experimental investigation of the mechanical behaviour of soil using laboratory test apparatus is prone to errors. One particular error is that due to membrane penetration; where the use of rubber membranes to enclose the test-specimen, set up in the HCA, induces an effect that can influence the specimen response during the test (Saada \& Puccini, 1988).

In the present study, an automated HCA was used to investigate the inherent anisotropy and membrane penetration of Leighton Buzzard sand test-specimens.

\subsection{Inherent anisotropy}

The particulate nature of soil leads to anisotropic strength and stiffness characteristics. Anisotropic behaviour can be divided into two distinct categories (Hoque et al., 1998):
1. Inherent anisotropy from the development of an anisotropic macro or micro fabric, for instance, after the deposition of the particles through air or water. Inherent anisotropic behaviour continues after stress state changes occur. This leads to anisotropic stiffness behaviour during isotropic stress changes (Jamiolkowski et al., 1991).

2. Induced anisotropy develops in a soil when anisotropic stress changes are applied.

The particular case of cross-anisotropic behaviour is only likely to occur for horizontally bedded soils where the horizontal stresses have always remained equal and the major principal stress has always acted either in the vertical or horizontal directions.

The HCA is a very useful tool for investigating the inherent anisotropy of soils. The magnitude and the direction of the three principal strains can be resolved from sample deformation measurements for isotropic loading conditions. The effect of the initial relative density on the inherent anisotropy of Leighton Buzzard sand test-specimens was investigated in the present study.

\subsection{Membrane penetration}

The penetration of the sample membrane into the interstices of a granular test-specimen changes whenever the effective confining stress alters. A systematic error in measured volume changes (during a drained test) or measured excess pore pressure (during an undrained 
test) ensues. A systematic error in measured volume changes results in errors when the actual inner and outer dimensions of the hollow cylindrical test-specimen are calculated from measured volume changes of the test-specimen itself and the inner bore cavity.

The magnitude of the membrane penetration into the interstices of the sand was assessed using the method proposed by Sivathayalan \& Vaid (1998) which is a non-destructive, test-specimen specific method for the assessment of membrane penetration in hollow cylindrical test-specimens.

\section{OVERVIEW OF THE HOLLOW CYLINDER APPARATUS}

The HCA used in the present study was developed at the National University of Ireland, Dublin (O'Kelly, 2000; Naughton, 2002). The test apparatus subjects a $100 \mathrm{~mm}$ outer diameter $\times 71 \mathrm{~mm}$ inner diameter $\times$ $200 \mathrm{~mm}$ high hollow cylindrical test-specimen to an inner pressure $\left(\mathrm{P}_{\mathrm{i}}\right)$, an outer pressure $\left(\mathrm{P}_{\mathrm{o}}\right)$, an axial load $(\mathrm{W})$, and a torque $(\mathrm{T})$, Figure 1a. The test apparatus is

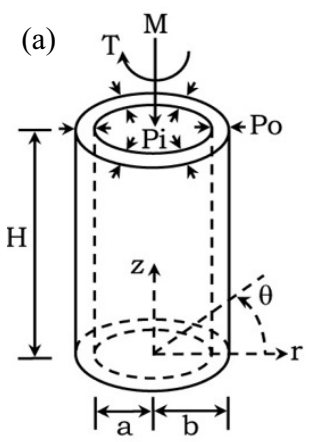

(b)
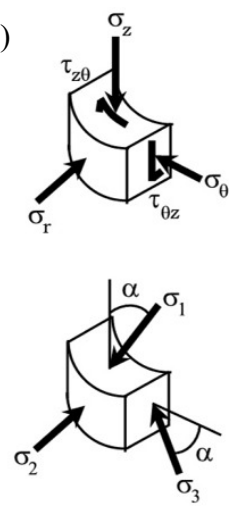

(c)

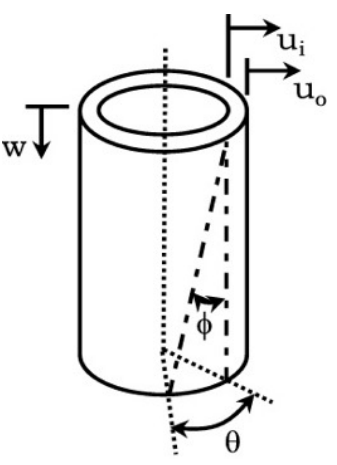

Figure 1. (a) System of pressures, axial and torsional loads applied to the test-specimen. (b) Resultant normal and principal stresses acting on an element of the test-specimen wall. (c) Deformational response of the test-specimen. close-loop controlled allowing precise regulation of the applied loads and pressures. Figure $1 \mathrm{~b}$ presents the resultant normal and principal stresses induced in an element of the test-specimen wall. The deformational response of the test-specimen is shown in Figure 1c.

The deformational response of the test-specimen is recorded using both internal and external instrumentation. The internal instrumentation is connected directly or is in close proximity to the test-specimen walls and measures the actual deformation occurring over a central gauge length of the test-specimen. Two proximity transducers measure the inner and outer displacements of the test-specimen walls $\left(\mathrm{u}_{\mathrm{i}}\right.$ and $\mathrm{u}_{\mathrm{o}}$, respectively) at mid height, while two modified doubleaxis Imperial College-type inclinometers record the axial normal $(\mathrm{w})$ and circumferential shear $(\theta)$ deformations over the middle third of the test-specimen. A single-axis inclinometer is also used to record the circumferential shear deformation.

The external instrumentation determines the axial normal and circumferential shear deformations from the movement of the loading mechanisms which apply the axial load and the torque to the test-specimen. Displacements of the inner and outer test-specimen walls are determined from measured volume changes of the test-specimen itself and the inner bore cavity.

The automated test apparatus is capable of regulating the induced stresses in the test-specimen to $0.5 \mathrm{kPa}$ during sample loading under either drained or undrained conditions. The test-specimen's deformational response is recorded using the internal and external instrumentation to $5.3 \times 10^{-5}$ strain and $6.3 \times 10^{-5}$ strain, or better, respectively.

\section{SAMPLE PREPARATION METHOD}

Hollow cylindrical test-specimens were formed using a wet-pluivation technique developed by O'Kelly (2000). Test-specimens are formed between inner and outer moulds using water-pluviation. Tapping the sides of the moulds causes the test-specimen to compact. Saturated test-specimens in very loose to loose states were formed in a single layer by depositing saturated sand through water. Pluviation has the added benefit that it replicates the sedimentation process and hence the fabric of many natural sand deposits. The preparation method provides a convenient means of studying the anisotropy of sand in the laboratory.

Leighton Buzzard sand test-specimens with a mean initial relative density of $17 \%$ were prepared using the above technique. Tapping the sides of the moulds was then used to achieve any desired target relative density up to a maximum value of $95 \%$. Naughton (2002) showed that the initial relative density of the testspecimens is not affected by the diameter of the depositing pipe and that the test-specimen can be 
reproduced to within $\pm 10 \%$ of a desired target relative density.

The variation in the initial relative density of the testspecimen is larger than the $\pm 2 \%$ reported by Vaid \& Negussey (1988) who also used a wet-pluviation sample preparation technique. The difference in the magnitude of this error occurs as a consequence of the smaller test-specimen size used in the present study and the limitations in determining the initial dimensions of the test-specimen to sufficient resolution. However, isotropic sample loading tests in the HCA indicated that the larger variation in the test-specimen's initial relative density did not significantly affect the repeatability of the constitutive response (Naughton, 2002).

\section{CHARACTERISTICS OF THE SAND AND INITIAL TEST-SPECIMEN PROPERTIES}

Fine-to-medium, white Leighton Buzzard sand was tested in the present study. Figure 2 presents a grading curve for the sand. Some physical properties of the sand are also summarized in Table 1.

\section{EXPERIMENTAL INVESTIGATIONS}

The test programme consisted of isotropic loading of five saturated test-specimens set up in the HCA. The deformational response of the test-specimens was recorded using the internal and external instrumentation. Four of the test-specimens where used to investigate the inherent anisotropy of the sand, while membrane penetration effects were investigated for all five test-specimens.

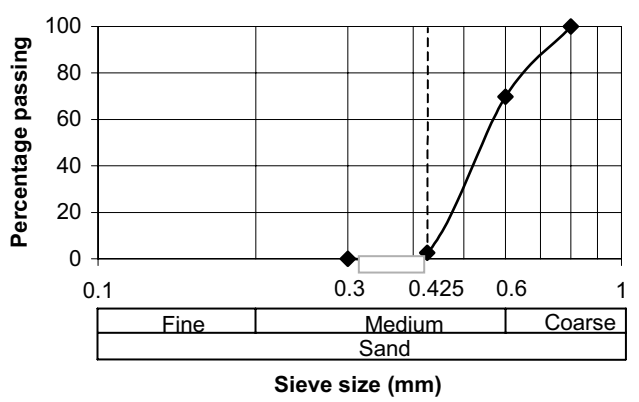

Figure 2. Grading curve for the Leighton Buzzard sand.

Table 1. Summary of properties of Leighton Buzzard sand.

\begin{tabular}{llllll}
\hline & $\begin{array}{l}\text { Coeffi- } \\
\text { cient of } \\
\text { Property }\end{array}$ & $\begin{array}{l}\text { Coeffi- } \\
\text { cient of }\end{array}$ & $\begin{array}{l}\text { Specific } \\
\text { curvature }\end{array}$ & $\begin{array}{l}\text { Maximum } \\
\text { voids } \\
\text { ratio }\end{array}$ & $\begin{array}{l}\text { Minimum } \\
\text { voids } \\
\text { ratio }\end{array}$ \\
\hline Value & 1.32 & 0.96 & 2.64 & 0.769 & 0.498 \\
\hline
\end{tabular}

\subsection{Initial test-specimen properties}

All test-specimens in the present study were formed using the wet-pluviation sample preparation technique described earlier. Physical properties and initial dimensions of the test-specimens are presented in Table 2.

\subsection{Investigation of inherent anisotropy}

Test-specimens IH13, IH45, IH72 and IH76 were isotropically consolidated from an initial effective stress of $100 \mathrm{kPa}$ (at the end of the sample saturation stage) to an effective stress of $200 \mathrm{kPa}$. The inherent anisotropy of the sand was analysed by comparing the three principal strain components which were resolved from the sample deformation measurements recorded using the internal instrumentation. For a truly isotropic material, an isotropic stress increment produces equal increments of the three principal strains. While it is not possible to completely separate the effects of inherent and induced anisotropy, this type of analysis does indicate trends and may be useful for determining if a testspecimen is cross anisotropic.

Figures 3, 4 and 5 present the relationships between the three principal strains. A linear relationship between any two principal strains is observed in all but one of the test-specimens, namely test-specimen IH45. The plot of the intermediate principal strain versus major principal strain for IH45 is highly non-linear with the intermediate principal strain data bunched between $-2 \times 10^{-3}$ and $-3 \times 10^{-3}$ strain. The intermediateto-minor principal strain plot for test-specimen IH45 is also non-linear but the non-linearity is not as pronounced as that observed in the intermediate-to-major principal strain plot.

Reasonable consistency is also observed in all plots for test-specimens IH72 and IH76, where the

Table 2. Summary of test-specimen properties.

\begin{tabular}{|c|c|c|c|c|c|}
\hline \multirow[b]{2}{*}{ Property } & \multicolumn{5}{|c|}{ Test-specimen designation } \\
\hline & IH13 & IH45 & $\mathrm{IH} 72$ & IH76 & MP83 \\
\hline $\begin{array}{l}\text { Mass of } \\
\text { sand }(g)\end{array}$ & 1160 & 1155 & 1162 & 1168 & 1172 \\
\hline $\begin{array}{l}\text { Dry density } \\
\left(\mathrm{Mg} / \mathrm{m}^{3}\right)\end{array}$ & 1.49 & 1.57 & 1.64 & 1.66 & 1.68 \\
\hline Void Ratio & 0.74 & 0.65 & 0.58 & 0.56 & 0.55 \\
\hline $\begin{array}{l}\text { Relative } \\
\text { density (\%) }\end{array}$ & 13.4 & 45.1 & 72.4 & 76.5 & 83.4 \\
\hline Height (mm) & 200.0 & 192.1 & 181.4 & 181.5 & 180.8 \\
\hline $\begin{array}{l}\text { Inner } \\
\text { radius (mm) }\end{array}$ & 35.5 & 35.5 & 35.5 & 35.5 & 35.5 \\
\hline $\begin{array}{l}\text { Outer } \\
\text { radius (mm) }\end{array}$ & 50.0 & 50.0 & 50.0 & 50.0 & 50.0 \\
\hline
\end{tabular}




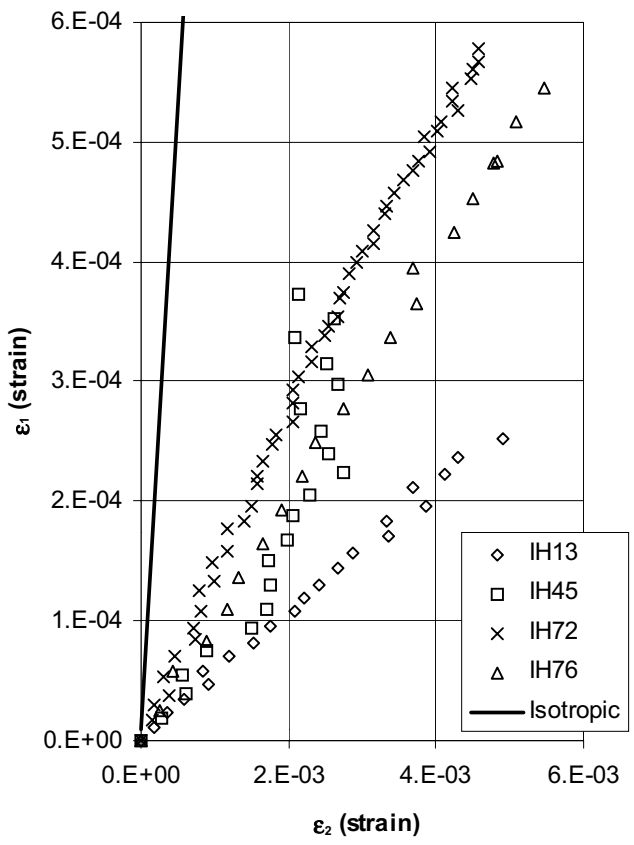

Figure 3. Plot of major $\left(\varepsilon_{1}\right)$ and intermediate $\left(\varepsilon_{2}\right)$ principal strains.

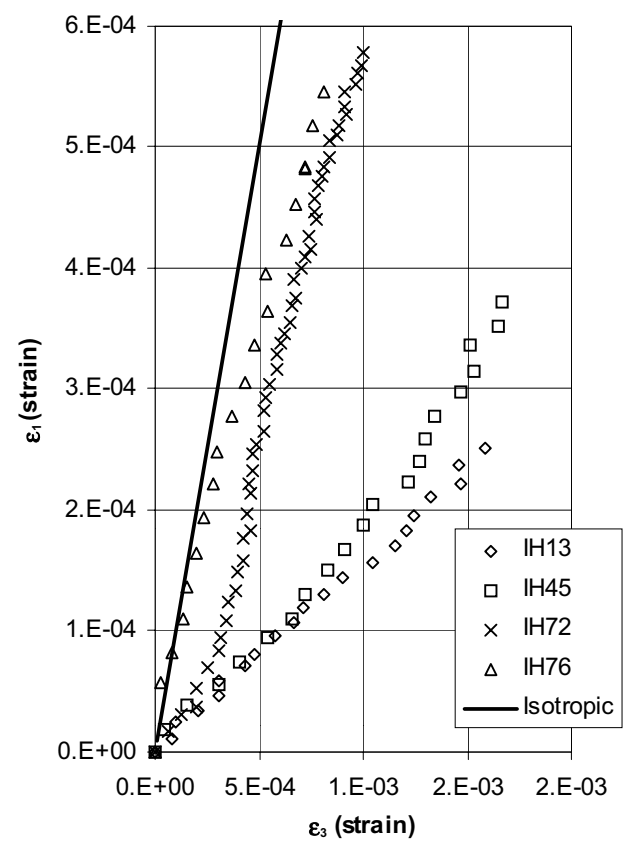

Figure 4. Plot of major $\left(\varepsilon_{1}\right)$ and minor $\left(\varepsilon_{2}\right)$ principal strains.

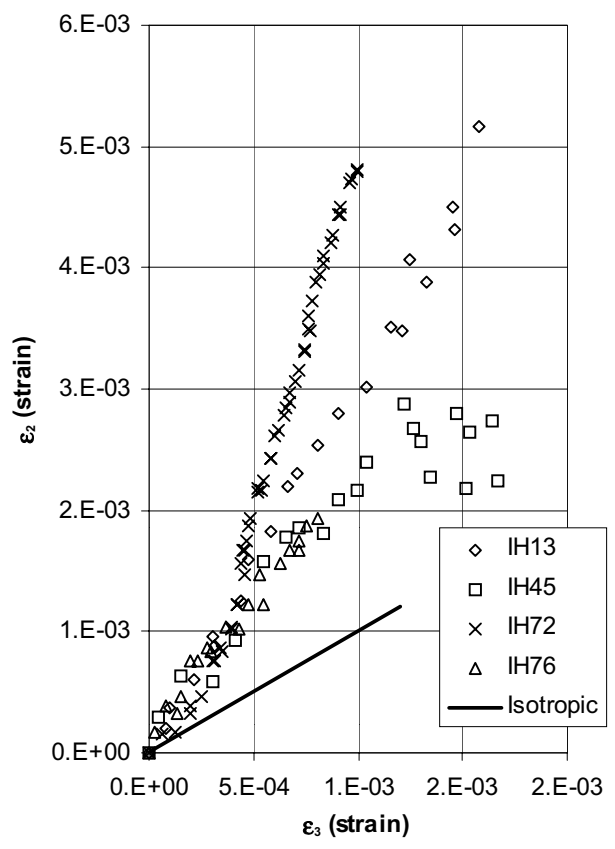

Figure 5. Plot of intermediate $\left(\varepsilon_{1}\right)$ and minor $\left(\varepsilon_{2}\right)$ principal strains.

initial relative densities are $72.4 \%$ and $76.5 \%$, respectively. In terms of the minor-to-major principal strain relationships, these test-specimens are close to being isotropic; however, this is the only plot where such behaviour is observed.

\subsection{Investigation of membrane penetration}

All five test-specimens were examined to assess the influence of the initial relative density on the degree of membrane penetration. The membrane penetration correction is obtained from the measured volumetric strains of the test-specimen and of the inner bore cavity for hydrostatic load increment/decrement stages together with measurement of the axial sample strain. The assessment method proposed by Sivathayalan \& Vaid (1998) assumes that the normal stresses at any point in the test-specimen remain the same in all directions. This assumption is valid as only extremely small radial shear stresses develop for hydrostatic loading in the HCA.

The unit membrane penetration can be calculated from the following equation (Sivathayalan \& Vaid, 1998):

$$
\varepsilon_{m}=\frac{\Delta V_{s m}-\Delta V_{b m}\left(\chi^{2}-1\right)}{\chi\left(A_{m b}+A_{m s}\right)}
$$




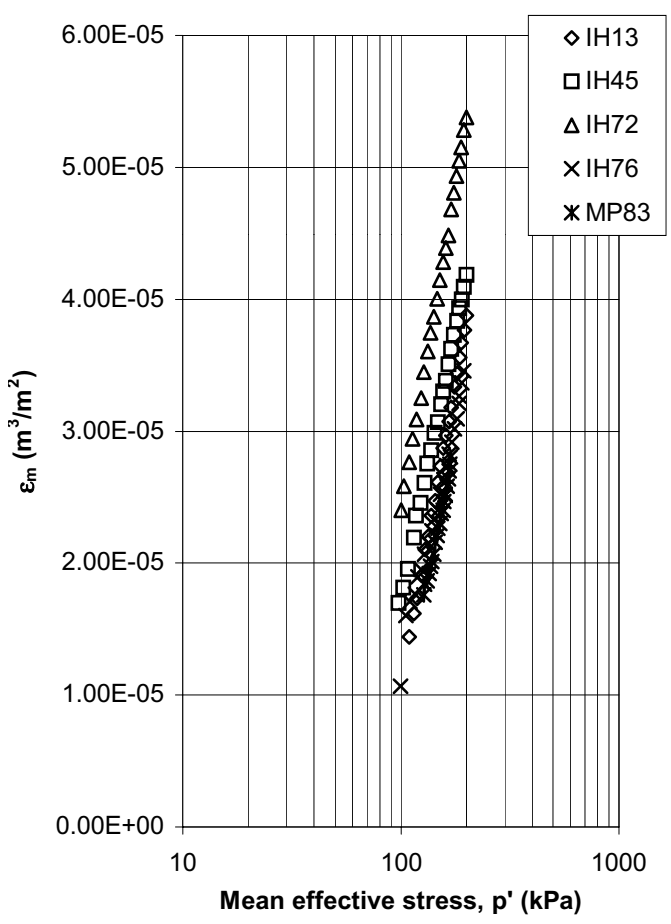

Figure 6. Plot of unit membrane penetration versus mean effective stress.

Table 3. Value of normalized unit membrane penetration for different relative densities.

\begin{tabular}{lll}
\hline & \multicolumn{2}{l}{$\begin{array}{l}\text { Normalized unit membrane } \\
\text { penetration, }\left(\mathrm{m}^{3} / \mathrm{m}^{2} / \mathrm{kPa}\right) \times 10^{-5}\end{array}$} \\
\cline { 2 - 3 } Test-specimen & Effective stress case & Total stress case \\
\hline IH13 & 4.067 & 8.106 \\
IH45 & 3.534 & 7.267 \\
IH72 & 4.297 & 8.805 \\
IH75 & 3.134 & 6.442 \\
MP83 & 3.487 & 7.039 \\
Mean & 3.704 & 7.532 \\
Standard deviation & 0.470 & 0.929 \\
\hline
\end{tabular}

Where, $\varepsilon_{\mathrm{m}}$ is the unit membrane penetration; $\Delta \mathrm{V}_{\mathrm{bm}}$ and $\Delta \mathrm{V}_{\mathrm{sm}}$ are the volume changes induced by penetration of the inner and outer membranes, respectively; $A_{m b}$ and $A_{m s}$ are the inner and outer surface areas of the testspecimen covered by the inner and outer membranes, respectively; and $\chi$ is the ratio of the outer-to-inner radii of the test specimen.

The experimental data obtained from the present study is plotted in terms of the mean effective stress in Figure 6. A linear relationship is observed between the unit membrane penetration and the mean effective stress.

The magnitude of the membrane penetration appears to be independent of the test-specimen's initial relative density as the relationships between the unit membrane penetration and the mean effective stress have similar gradients.

Values of normalized unit membrane penetration (expressed in terms of both mean effective and total stresses) obtained for different relative densities of Leighton Buzzard sand are presented in Table 3.

\section{DISCUSSION OF RESULTS}

The degree of inherent anisotropy was analysed using linear regression of the experimental strain plots. The gradients and linear regression coefficient for the data are presented in Table 4. The linear regression produced good to very good regression coefficients. An isotropic material would have a gradient of unity. The data for test-specimen IH45 in Table 4 is taken from the early linear response part of the test.

The data indicates a higher deformability of the sand in the horizontal direction than in the vertical direction. The linear relationships between the strain components indicate that the inherent anisotropy of the sand is not affected by increases in the mean effective stress applied under isotropic loading conditions. Both these observation are consistent with data for a medium Ottawa sand presented by Vaid \& Sayao (1995).

From the intermediate-to-minor principal strain data shown in Figure 5 and Table 4, all the test-specimens are observed to be anisotropic in the horizontal direction

Table 4. Regression data for anisotropic analysis.

\begin{tabular}{|c|c|c|c|c|c|c|}
\hline \multirow[b]{3}{*}{ Test-specimen } & \multicolumn{6}{|c|}{ Strain component relationship } \\
\hline & \multicolumn{2}{|l|}{$\varepsilon_{2}-\varepsilon_{1}$} & \multicolumn{2}{|l|}{$\varepsilon_{3}-\varepsilon_{1}$} & \multicolumn{2}{|l|}{$\varepsilon_{2}-\varepsilon_{3}$} \\
\hline & Gradient & $\mathrm{R}^{2}$ & Gradient & $\mathrm{R}^{2}$ & Gradient & $\mathrm{R}^{2}$ \\
\hline $\mathrm{IH} 13$ & 0.0511 & 0.992 & 0.1574 & 0.995 & 3.0768 & 0.992 \\
\hline $\mathrm{IH} 45$ & 0.0776 & 0.954 & 0.2026 & 0.979 & 2.3540 & 0.961 \\
\hline $\mathrm{IH} 72$ & 0.1243 & 0.991 & 0.5565 & 0.944 & 4.4610 & 0.927 \\
\hline $\mathrm{IH} 76$ & 0.0959 & 0.998 & 0.6940 & 0.982 & 3.3320 & 0.981 \\
\hline
\end{tabular}


and appear to have a similar relationship irrespective of the initial relative density. The mean gradient in the cross direction was found to be 3.077 , with a standard deviation of 0.874 . This trend could be attributed to the sample preparation technique. Tapping the sample moulds under $K_{o}$ conditions would have a far more pronounced effect on the sand properties in the vertical direction than in the horizontal direction as the relative density increases. This explanation is verified by examining the intermediate-to-minor principal strain response for test-specimen IH13. This test-specimen did not experience any tapping during preparation but has a similar intermediate-to-minor principal strain relationship to the other test-specimens which all experienced various amounts of tapping during sample preparation to achieve target initial relative densities.

The experimental data indicates that the degree of inherent anisotropy (expressed in terms of minorto-major and intermediate-to-major principal strains) decreases with increasing relative density, which is consistent with observations reported by Vaid \& Sayao (1995). However, the degree of cross anisotropy remains constant irrespective of the initial relative density of the test-specimen.

Sivathayalan \& Vaid (1998) referred to the gradient of the unit membrane penetration versus logarithm mean effective stress, as the normalized unit membrane penetration whereas Frydman et al. (1973) defined the normalized unit membrane penetration in terms of total stress. Sivathayalan \& Vaid (1998) and Frydman et al. (1973) produced relationships between the mean particle diameter and the normalized unit membrane penetration. These predictions are compared with the observed data for the Leighton Buzzard sand in Table 5. The measured membrane penetration is less than that predicted by Sivathayalan \& Vaid (1998) and Frydman et al. (1973). However considerable scatter does exist in the experimental data used by Sivathayalan \& Vaid (1998) and Frydman et al. (1973) in deriving their respective relationships.

The method for assessing the degree of membrane penetration proposed by Sivathayalan \& Vaid (1998)

Table 5. Comparison between experimental results and predictive method.

\begin{tabular}{lll}
\hline & $\begin{array}{l}\text { Normalized unit membrane } \\
\text { penetration }\left(\mathrm{m}^{3} / \mathrm{m}^{2} / \mathrm{kPa}\right) \times 10^{-5}\end{array}$ \\
\cline { 2 - 3 } & Effective stress case & Total stress case \\
\hline $\begin{array}{l}\text { Observed } \\
\begin{array}{l}\text { Sivathayalan \& } \\
\text { Vaid (1998) }\end{array}\end{array}$ & 3.704 & 7.532 \\
$\begin{array}{l}\text { Frydman et al. } \\
\text { (1973) }\end{array}$ & - & - \\
\hline
\end{tabular}

and discussed above was integrated into the closed-loop control program developed for the HCA. The magnitude of the membrane penetration was calculated during the early isotropic loading stage of a test and then used to correct subsequent test stages for the effects of membrane penetration.

\section{CONCLUSIONS}

The hollow cylinder apparatus is ideal for investigating the inherent anisotropy of soil. The inherent anisotropy of Leighton Buzzard sand was found to be independent of the mean effective stress but dependent on the initial relative density of the test-specimen. The inherent anisotropy in the vertical-to-horizontal directions was found to decrease as the initial relative density increased. A wet-pluviation technique, used to form the test-specimens, resulted in a crossanisotropic response which was independent of both the initial relative density of the test-specimen and the mean effective stress.

The magnitude of the membrane penetration was successfully calculated using a new non-destructive, specimen specific, test procedure. The procedure was integrated in the control program for the HCA. The magnitude of the membrane penetration was found to be independent of both the relative density and the mean test-specimen stress. Reasonable agreement was observed between the experimental normalized unit membrane penetration and that determined from other methods, which are based on the mean particle diameter of the soil.

\section{ACKNOWLEDGEMENTS}

The HCA described in the paper was developed at the National University of Ireland, Dublin. The authors would like to acknowledge the research funding providing by the Department of Civil Engineering, National University of Ireland, Dublin.

\section{REFERENCES}

Hoque, E. \& Tatsuoka, F., 1998. Anisotropy in elastic deformation of granular materials. Soils and Foundations, Vol. 38, No. 1.

Frydman, S., Zeitlen, J.G. \& Alpan, I., 1973. The membrane effect in triaxial testing of granular soils. Journal of Testing and Evaluation, Vol. 1, No. 1.

Naughton, P.J., 2002. The investigation of Leighton Buzzard sand in a new hollow cylinder apparatus. PhD thesis submitted to, University College Dublin, Ireland.

O'Kelly, B.C., 2000. Development of a new apparatus for hollow cylinder testing. $\mathrm{PhD}$ thesis, National University of Ireland, Dublin. 
Saada, A.S. \& Puccini, P.M., 1986. Deformation behaviour of anisotropic dense sand under principal stress axes rotation, Discussion. Soils and Foundations, Vol. 26, No. 4.

Sivathayalan, S. \& Vaid, Y.P., 1998. Truly undrained response of granular soils with no membrane penetration effects. Canadian Geotechnical Journal, Vol. 35, pp. $730-739$.
Vaid, Y.P. \& Negussey, D., 1988. Preparation of reconstituted sand specimens. Advanced triaxial testing of Soil and Rock, ASTM STP 977, ASTM, USA.

Vaid, Y.P. \& Sayao, A., 1995. Proportional loading behaviour of sand under multiaxial stresses. Soils and Foundations, Vol. 35, No. 3 . 
